Volume 8. No. 6, June 2020

International Journal of Emerging Trends in Engineering Research

Available Online at http://www.warse.org/IJETER/static/pdf/file/ijeter23862020.pdf

https://doi.org/10.30534/ijeter/2020/23862020

\title{
MUS-Tracker: An IoT Based System in Controlling and Monitoring of Beehives
}

\author{
Mustafa Man ${ }^{1 *}$, Wan Aezwani Wan Abu Bakar ${ }^{2}$, Muhammad Azri Bahruddin Bin Abdul Razak ${ }^{3}$ \\ ${ }^{1,3}$ Faculty of Ocean Engineering Technology and Informatics, \\ University Malaysia Terengganu (UMT), \\ 21030 Kuala Nerus, Terengganu, Malaysia. \\ mustafaman@umt.edu.my \\ ${ }^{2}$ Faculty Informatic and Computing, Universiti Sultan Zainal Abidin, Besut Campus, 22200 Besut, \\ Terengganu. Malaysia. \\ wanaezwani@unisza.edu.my
}

\begin{abstract}
The problem of colony is theft becoming more serious and is not only happening in the east coast, but has also been reported in other farms. In the past, theft only applied to logs/sticks. But lately, this has been the case with the colonies in the hive box. As demand for such goods is high and resold at high prices, it is not surprising that these cases of theft have become more severe lately. To counteract this bad activity, a new idea and method was introduced with the use of specially designed IoT technology known as Mus-Tracker. This Beehives design comes with one GPS/GSM module slot. Beehives being stolen or taken or relocated will allow it to be tracked by the owner by simply sending a message to the GPS/GSM tracker module. Once the location has been identified, the tracking process will be able to perform it quickly and easily detect the beehives. Hopefully with this new system, it will solve the problem of theft based on the new method even though the cost is relatively high at first.
\end{abstract}

Key words: Internet of things (IoT), Beehives, GPS/GSM Trackers, Tracking and Monitoring Process.

\section{INTRODUCTION}

Beehives is a structure in which bees are kept, typically in the form of a dome or box. The word 'beehive' is commonly used to describe the nest of any bee colony, scientific and professional literature distinguishes nest from hive. Hive is used to describe structures used by human to house a honey bee nest. Because of high demand in honey bee, the series of beehive's theft is spreading as well [1]. Since the colony theft problem has been frequently reported not only in the east coast states, but also in other areas of livestock breeding. Previously, they only targeted on logs. But the current trend is to the colonies in the boxes. These thefts are dared to break into the housing boundary of beehives owner for that purpose.
Their presence will not only endanger to the people in the house but as well as to the colony itself [2].

The main issue is when there exist certain individuals who abet this thief by buying a colony at a bargain price as compared to current market prices. Those who abet this may be collectors of colonies who buy and then sell to breeders. There are also breeders who are willing to buy this log though they know the source of the $\log$ is quite suspicious. This situation is similar to the problem of losing iron products to sellers to bad buyers whereas the badger buyers themselves know that the goods are stolen goods [3]. Because the demand for the goods is high and can be reclaimed at a high price, then this scenario is getting more severe.

\section{MUS-TRACKER: IOT BASED SOLUTION}

The 'Mus-Tracker' project is proposed to solve the issue by tracking and monitoring of beehives via GSM/GPS tracker technology. GSM stands for Global System for Mobile as a mobile tracker while GPS Tracker is a device normally carried by a moving vehicle or person that use Global Positioning System to determine and track its precise location and its carrier [3]. The GPS system uses Global Navigation Satellite System (GNSS) network that incorporates a range of satellites using microwave signals. The signals are transmitted to GPS devices to give information on location, vehicle speed, time and direction. The GSM/GPS technology is fast and easy in getting information about the current location of the subject you are monitoring.

What about the cost of getting information? Very cheap, average only 5 cents for every SMS message charge charged by service providers like Maxis, Celcom, Digi and so on. It does not take into account whether the phone SIM card whether using prepaid or postpaid. There are several key features that allow GPS/GSM Tracker to work with the user to track and monitor for a project or activity. Figure 1 shows a GPS GSM Tracker product description. 

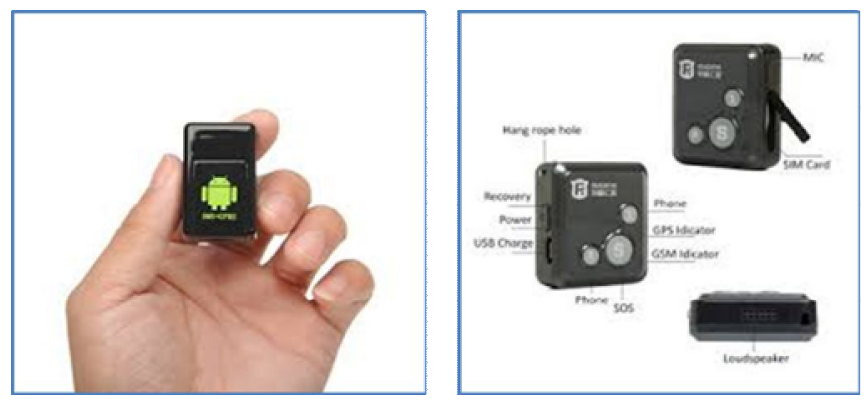

Figure 1: Mini GPS/GSM Tracker Products

The idea is such that the design of beehives box should have a small slot that can place the GPS/GSM Tracker module and simplifies the process of charging the module's battery. The Mus-Tracker tracking system has five (5) modules, namely GPS receiver module, ARM Cortex-M3 STM32 minimum microcontroller system, GSM/GPRS module, push button, and battery. These modules are installed into a known as GPS/GSM Tracker. Figure 2 shows the picture of the process.

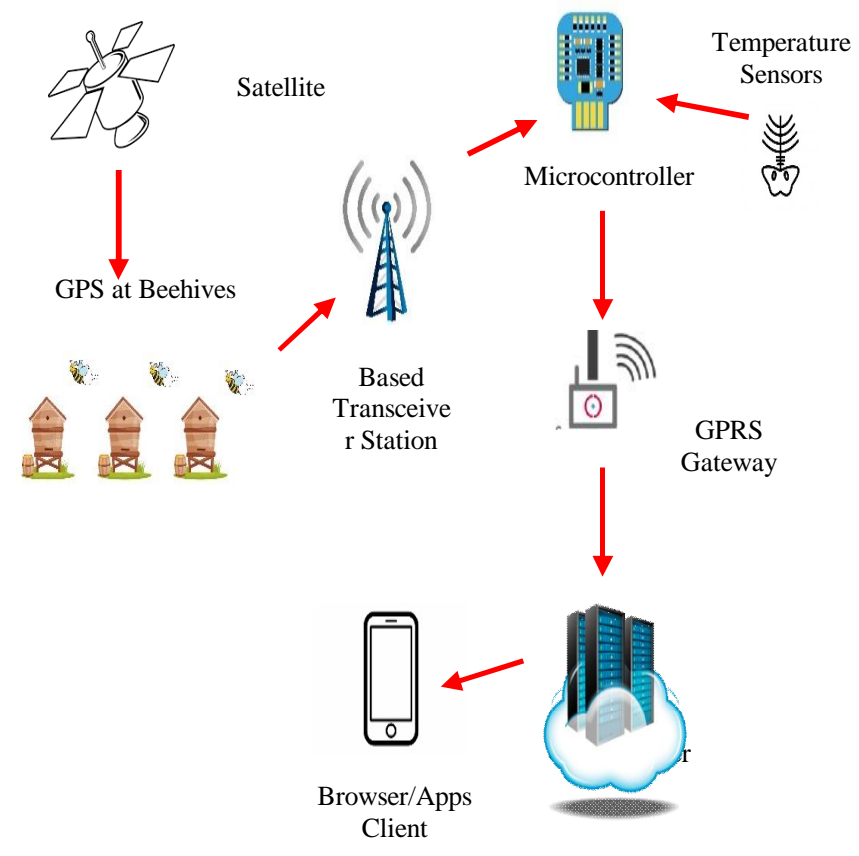

Figure 2: The Basic Concept of MUS-Tracker System Design

Figure 3 illustrates the design of the beam beehives box with the position of GPS/GSM Tracker in it. Based on the Meliponiculture Integrated Locking System (MILOS)[4], a set of GPS/GSM Tracker modules is inserted into the set of beehives box. This system is able to give twice the safety of the hive. For example, all the stolen or broken or removed beehives is tracked by the owner by GPS/GSM tracker module message sending. Once the location is identified, then it easily tracks and detects the thief. Fast tracking process could reduce and eliminate the issue of stolen or lost of beehives regardless of the quite high cost required during early setup configuration.

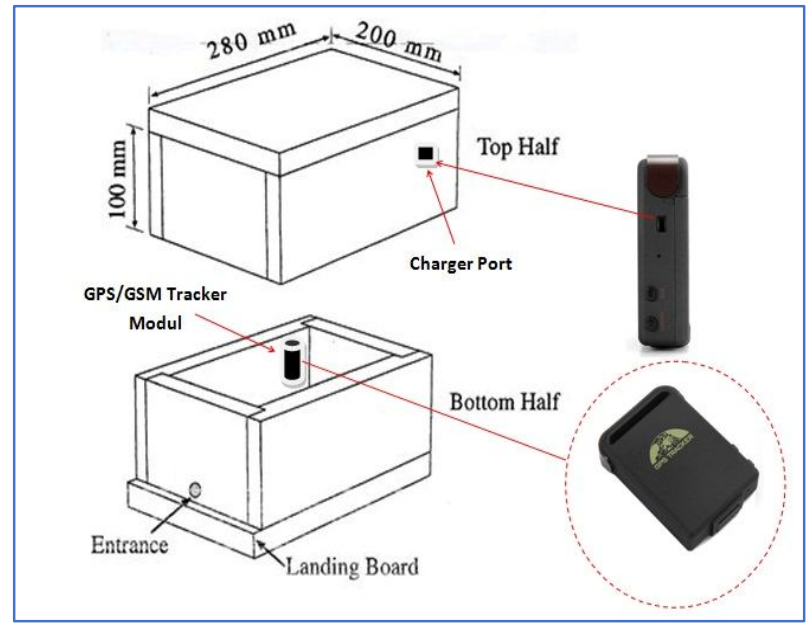

Figure 3: Overview of GPS/GSM Tracker Position in beehives

\section{HARDWARE AND SOFTWARE DESIGN AND TESTING}

The main hardware component of Mus-Tracker is Wemos D1 Mini PRO, an ESP8266 based of wireless 802.11 (Wifi) microcontroller development board [5]. We use the Temperature Sensor, DHT11 as the second component [6]. It is a low-cost and low-power wireless sensor node for collecting the information of temperature and humidity based on the requirements of greenhouse and hatchery. The low power consumption MSP430F122 as the core, temperature humidity sensor and single RF transceiver NRF401 is realized to be an effective data acquisition and reliable data transmission. It has advantages such as low power consumption, low cost, high integration, small size and stable operation.

Third component is GPS GY NEO6MV2, a low cost but powerful GPS receiver that based on the famous and high-end u-Blox Neo-6M GPS module [7]. It comes with small battery for hot-start, and there is built-in EEPROM. An external ceramic antenna that connect to the board via U.FL, a solid connector for better signal reception. It can operate from 3.3V to $5 \mathrm{~V}$ system where all $5 \mathrm{~V}$ Arduino board i.e. CT-UNO, Maker-UNO, Arduino-UNO, Mega and Leonardo. Fourth component is MT3608 with 6-pin SOT23 current mode step-up converter intended for small, low power applications. The MT3608 switches at $1.2 \mathrm{MHz}$ and allows the use of tiny, low cost capacitors and inductors $2 \mathrm{~mm}$ or less in height. Internal soft-start results in small inrush current and extends battery life. The MT3608 features automatic shifting to pulse frequency modulation mode at light loads. The MT3608 includes under-voltage lockout, current limiting, and thermal overload protection to prevent damage in the event of an output overload [8]. 
The fifth component is the 3.7V $186503000 \mathrm{mAh}$ battery, a rechargeable lithium battery with No memory effect that could recharge up to 1000 cycles. It is a $100 \%$ quality Japanese battery cells with $100 \%$ Q.C. of every battery [9]. Last component is the 5W 5V USB Portable Solar Panel that made of high efficiency Monocrystalline silicon cells, the conversion rate is high for collecting source of power to the batteries as a backup. It offers small attenuation, good reliability and long service life. The use of high-quality plastic frame, high strength, to ensure a higher degree of wind resistance and riot performance. It can adapt to a variety of complex and harsh weather conditions. Figure 4 illustrates a complete design of Mus-Tracker circuit board and Table 1 details out all the component's functionality [10].

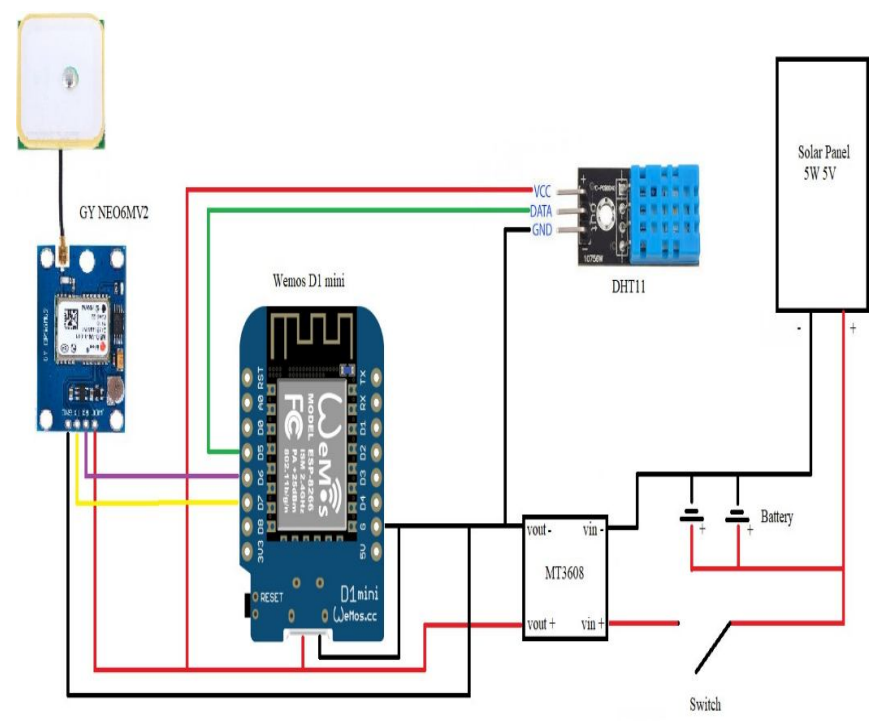

Figure 4: Circuit Design Diagram for MUS-Tracker hardware components

Table 1: MUS-Tracker component's functionality

\begin{tabular}{|c|l|}
\hline Components & \multicolumn{1}{c|}{ Functions } \\
\hline Temperature Sensor DHT11 & Collect temperature data \\
\hline GATA device GY NEO6MV2 & Collect location data \\
\hline Microcontroller Wemos D1 Mini & Control the behavioral of the \\
\hline & device \\
\hline GND & \\
\hline &
\end{tabular}

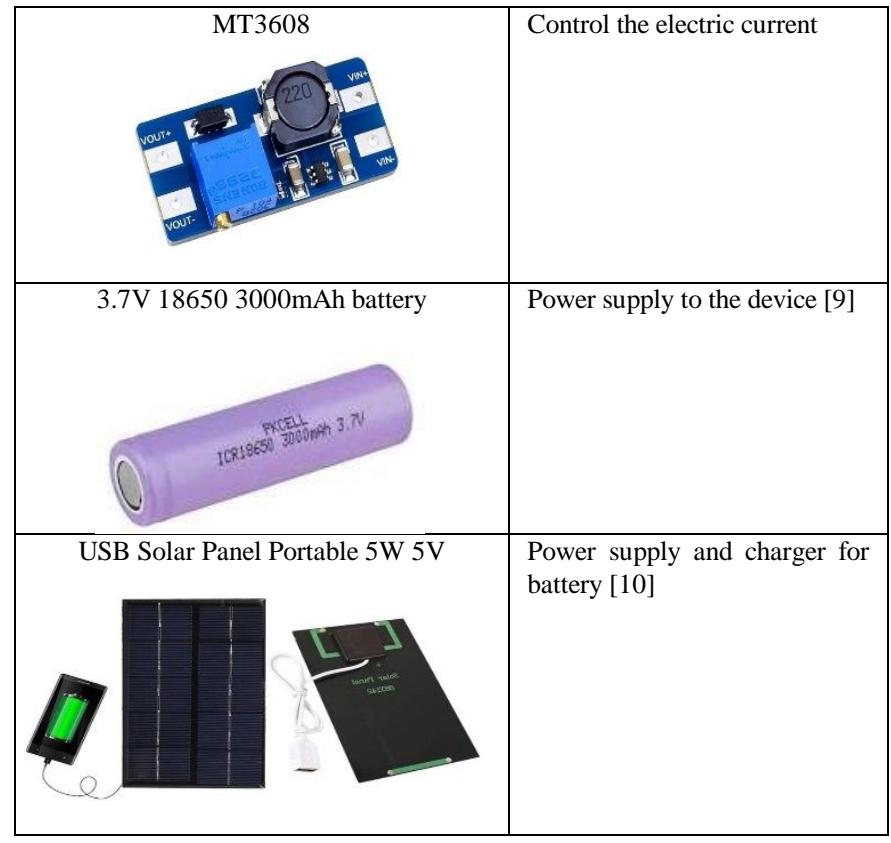

Experimentations are conducted under Core i5 Processor with 4GB RAM and NVIDIA GeForce 940M. A 2GB Dedicated VRAM and 120 GB SSD are used with storage of 1TB HDD. With Win10 environment, MUS-Tracker application can be surf via any browsers i.e. Google Chrome, Internet Explorer, and Mozilla Firefox. We use NetBeans 8.2 platform to develop software while Apache Tomcat is a web server that supports for the functionality of the modules. We use MySQL to manage database of the system and HTML5, JavaScript, Cascading Style Sheets (CSS) as well as Java for page scripting.

\section{RESULT AND DISCUSSION}

MUS-Tracker system is written by using Arduino IDE 1.8.9 and send through micro USB into microcontroller Wemos D1 mini. Figure 5 illustrates the sample of snapshot screens for MUS-Tracker System Dashboard.

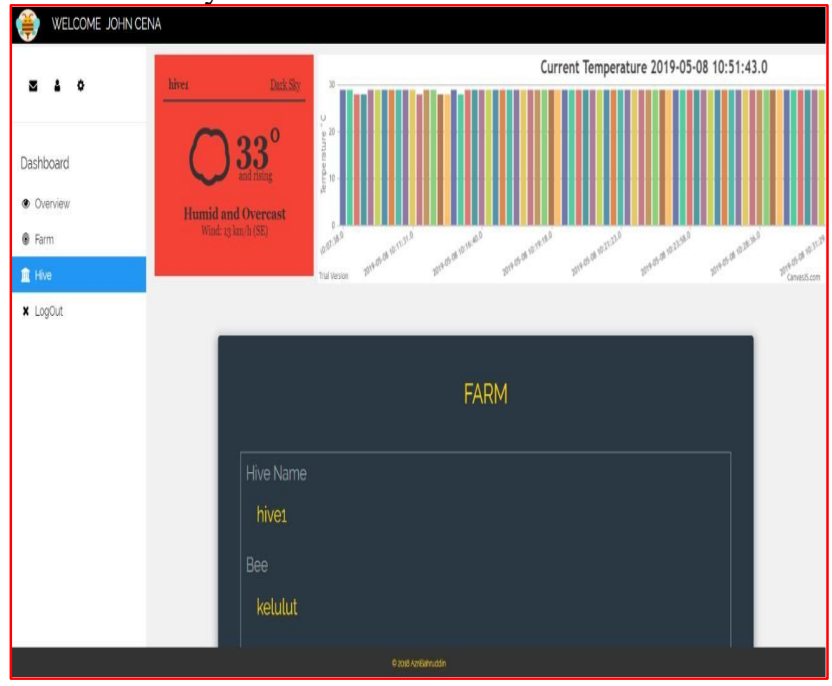

Figure 5: MUS-Tracker System Dashboard 
The MUS-Tracker dashboard (refer to figure 6) enables each beehive to be monitored in real time through its location using Google map [12,13]. The bar graph for the latest temperature data is shown in colors (blue and red). The dashboard also gives user notification when the distance hive from set location is out of range or the temperature of hive is higher than maximum temperature or lower than minimum temperature. User can click on the white arrow to see the notification details.

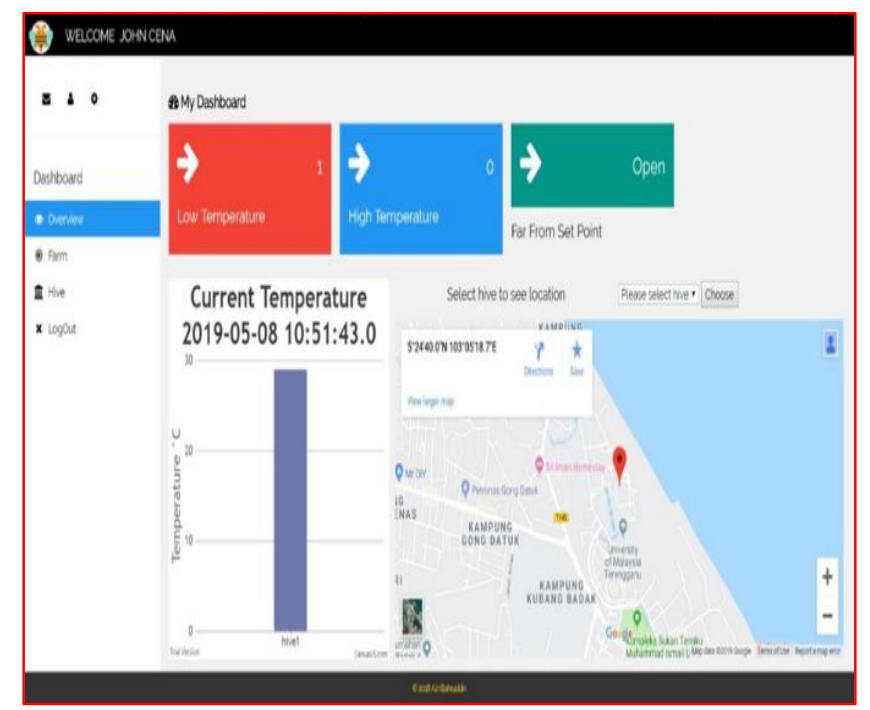

Figure 6: MUS-Tracker System Dashboard for Temperature Level

\section{CONCLUSION}

In conclusion, it is hoped that this project will run smoothly and its prototype can be completed and can be beneficial to beehive's special breeders in Malaysia.

\section{ACKNOWLEDGEMENT}

Our gratitude to UMT Grant with VOT 53258: A GSM/GPS Tracker Technology in Tracking Monitoring of Beehives our financial support from. And all faculty members of UMT and UniSZA for meaningful comments and suggestions and proofreading for spelling errors and synchronization consistencies.

\section{REFERENCES}

1. I. Mohd and W. I. W. Iryani. (2018). "Development of stingless beekeeping projects in Malaysia". E3S Web of Conferences. 52. 00028. 10.1051/e3sconf/20185200028.

2. P. Paramita, M. Shuhairie. (2008). GPS Navigation System. Malaysia: Universiti Malaysia Pahang.

3. M. Mustafa, W. A, Bakar, M. A. B. A. Razak, (2019). "An Intelligent Stingless Bee System with Embedded IOT Technology". International Journal of Recent Technology and Engineering (IJRTE) ISSN: 2277-3878, Volume-8, Issue-3, September 2019 https://doi.org/10.35940/ijrte.C4124.098319
4. M. Z. Mustafa, N. S. Yaacob, S. A. Sulaiman. "Reinventing the honey industry: opportunities of the stingless bee". Malays J Med Sci. 2018;25(4):1-5. https://doi.org/10.21315/mjms2018.25.4.1.

5. R. K. Kodali, A. Sahu, (2016, December). "An IoT based weather information prototype using WeMos". In 2016 2nd International Conference on Contemporary Computing and Informatics (IC3I) (pp. 612-616). IEEE. https://doi.org/10.1109/IC3I.2016.7918036

6. Y. M. Han and J. P. Zhao, (2011). "Design of temperature humidity wireless sensor network node based on DHT11". Journal of Jinggangshan University (Natural Science), 1, 018.

7. A. A. Yakimenko, D. A. Bogomolov, A. E. Morozov, and A. V. Sokolova, (2017, September). "Development and research of the information system for monitoring the condition of the road surface using mobile devices to optimize logistics and repair costs". In 2017 International Multi-Conference on Engineering, Computer and Information Sciences (SIBIRCON) (pp. 190-192). IEEE. https://doi.org/10.1109/SIBIRCON.2017.8109868

8. V. Errico, M. Ricci, A. Pallotti, F. Giannini and G. Saggio, (2018, June). "Ambient assisted living for tetraplegic people by means of an electronic system based on a novel sensory headwear: Increased possibilities for reduced abilities". In 2018 IEEE International Symposium on Medical Measurements and Applications (MeMeA) (pp. 1-6). IEEE.

https://doi.org/10.1109/MeMeA.2018.8438638

9. $3.7 \mathrm{~V} 18650 \quad 3000 \mathrm{mAh}$ battery. Available: https://www.makerlab-electronics.com/product/3-7v-30 00mah-18650-lithium-ion-battery/.

10. USB Solar Panel Portable 5W 5V. Available: https://www.aliexpress.com/item/32841181367.html.

11. Tinkercad from Mind to Design. Available: https://www.tinkercad.com/.

12. Google Maps. Available: https://www.google.com/maps/@5.752407,102.636748 $8,15 z$, retrieved on 27 June 2019.

13. C. J. Kaufman, Rocky Mountain Research Lab., Boulder, CO, private communication, May 1995. 